\title{
Education and HIV/AIDS Prevention:
}

\author{
Evidence from a randomized evaluation in Western Kenya
}

\author{
Esther Duflo* \\ Pascaline Dupas $^{* *}$ \\ Michael Kremer ${ }^{* * *}$ \\ Samuel Sinei ${ }^{* * * *}$
}

June 2006

\begin{abstract}
We report results from a randomized evaluation comparing three school-based HIV/AIDS interventions in Kenya: 1) training teachers in the Kenyan Government's HIV/AIDS-education curriculum; 2) encouraging students to debate the role of condoms and to write essays on how to protect themselves against HIV/AIDS; and 3) reducing the cost of education. Our primary measure of the effectiveness of these interventions is teenage childbearing, which is associated with unprotected sex. We also collected measures of knowledge, attitudes, and behavior regarding HIV/AIDS. After two years, girls in schools where teachers had been trained were more likely to be married in the event of a pregnancy. The program had little other impact on students' knowledge, attitudes, and behavior, or on the incidence of teen childbearing. The condom debates and essays increased practical knowledge and self-reported use of condoms without increasing self-reported sexual activity. Reducing the cost of education by paying for school uniforms reduced dropout rates, teen marriage, and childbearing.
\end{abstract}

Key words: HIV/AIDS prevention; school; Africa; Kenya; Youth; developing countries

\footnotetext{
* Department of Economics and Poverty Action Lab, MIT.

** Paris-Jourdan Science Economiques.

*** Department of Economics, Harvard University; Brookings Institution; NBER; Poverty Action Lab, MIT.

**** Jomo Kenyatta University of Agriculture and Technology, Kenya.

The authors thank ICS Africa, the Kenya National AIDS Control Council, the Kenya Institute of Education and the Kenya Ministry of Education, Science and Technology for their cooperation in all stages of the project, and would especially like to acknowledge the contributions of Chip Bury, Robert Namunyu, Laban Benaya, Carol Nekesa, Grace Makana and her staff, Willa Friedman, Jessica Leino, Jessica Morgan, Ian Tomb and Paul Wang, without whom the project would not have been possible. Gratitude is also extended to the teachers and school children of Bungoma, Butere-Mumias and Busia districts for participating in the study. Mutsa Chironga provided excellent research assistance. We are grateful for financial support from the Partnership for Child Development and the World Bank. All errors are our own.
} 


\section{Introduction}

The future course of the AIDS epidemic in Africa depends in large part on the behavior of the next generation. Children between the ages of 5 and 14 have been referred to as a 'window of hope' because they have low infection rates and have not yet established patterns of sexual behavior (Kelly 2000, Bundy 2002). The majority of children in Africa attend at least some primary school, and schools offer an opportunity to reach these children. There is, however, considerable debate on whether scalable school-based HIV/AIDS education programs can be effective in limiting the spread of HIV/AIDS among youth. Will teachers actually teach these curricula? If the curricula are taught, can they affect knowledge, attitudes, or behavior? Even if these programs have an impact, are these programs an effective use of resources relative to other alternatives, in particular simply subsidizing school attendance? There is also intense debate over the content of these programs. Will discussion of condoms spur increased use of condoms? Will it spur increased sexual activity?

Although many countries have incorporated HIV/AIDS education in their school curriculum, there is limited rigorous evidence from controlled trials on these questions. ${ }^{1}$ Gallant and Maticka-Tyndale (2004) review 11 school-based HIV/AIDS risk reduction programs in Africa and report only one randomized controlled trial. Stanton et al. (1998) found that AIDS education in Namibia reduced some self-reported HIV risk behaviorssuch as sex with multiple partners in the last month and sex without a condom-among sexually inexperienced 15 to 18 year olds, but that reductions were not significant for all

\footnotetext{
${ }^{1}$ Kinsman et al. 2001, UNAIDS 1997, Kirby et al. 1985, 1994, 1995, Kirby and Coyle 1997, Klepp et al. 1997, Aplasca et al. 1995.
} 
program participants. Stanton et al (1998) like most existing studies of the effectiveness of HIV education programs, rely on self-reported information about knowledge and behavior. $^{2}$ However, self-reported data on behavior may suffer from social desirability bias if subjects report what they think the interviewer wants to hear (Aral et al. 1996, Mellanby et al. 1995).

To our knowledge, there is only one randomized trial of sexual health education in Africa that looks at biological outcomes. Results from this study became available subsequent to the Gallant and Maticka-Tyndale (2004) review. MEMA Kwa Vijana, conducted in 10 communities of rural Tanzania, included in-school education, youthfriendly health services, and community-based condom promotion and distribution. Ten other communities served as a comparison group. The program led to improved knowledge, reported attitudes and reported behaviors, but an evaluation found no consistent impact on biological indicators of HIV, other STIs, or pregnancy (DFID, 2004). However, since the incidence of these events is low among adolescents, the sample size of 10 treatment and 10 comparison communities did not provide enough statistical power to detect changes smaller than $50 \%$ (Hayes et al, 2005). Since programs would be cost effective even at much lower efficacy levels, it is difficult to draw firm conclusions.

This paper reports results from a randomized evaluation of three different schoolbased interventions in Kenya: 1) training teachers in the HIV/AIDS-education curriculum designed for primary schools by the Kenyan Government; 2) encouraging students to debate the role of condoms, as suggested in the Kenyan Governments' Facilitator's

\footnotetext{
${ }^{2}$ See Gallant and Maticka-Tyndale [2004] for a review.
} 
Handbook, and to write essays about how they can protect themselves from HIV/AIDS; and 3) reducing the cost of education to keep children in school longer. To shed light on the role of risk reduction, we also compare our results to those of Dupas (2005) who conducted, in the same schools, a randomized evaluation of the impact of informing teenagers about variation in HIV rates by age and sex.

The study involved 70,000 students from 328 primary schools. Our primary measure of the effectiveness of these interventions is teenage childbearing, which is associated with unprotected sex, the main driver of HIV/AIDS in this population. We also collected measures of knowledge, attitude, and behavior regarding HIV/AIDS. We find that after two years the teacher training program had little impact on students' knowledge and self-reported sexual activity and condom use, or on teen childbearing. However, it increased students' tolerance toward people with HIV/AIDS and girls exposed to the program were more likely to be married to the fathers of their children. Its overall impact on exposure to the HIV risk is unclear. Debates among peers on the role of condoms and an associated essay competition on ways students could protect themselves against AIDS increased self-reported use of condoms, without increasing self-reported sexual activity. (The condom debate and essay competition took place too recently for us to be able to detect any possible reduction in childbearing.) Dupas (2005) reports that informing girls about variation in HIV rates by age and sex led girls to avoid crossgenerational partnerships, which are particularly risky. Reducing the cost of education by paying for school uniforms reduced dropout rates and the incidence of teen childbearing.

The remainder of the paper proceeds as follows. Section 2 provides background information on the Kenyan context. Section 3 describes the programs. Section 4 
discusses the data and the estimation strategy. Section 5 presents the empirical results. The final section concludes.

\section{Background on HIV/AIDS in Kenya}

\section{a. HIV Prevalence}

Until recently AIDS prevalence in Kenya was estimated to be around 15\%, based on data from antenatal clinics. The 2003 Kenya Demographic and Health Survey (KDHS), which included HIV testing of survey respondents, estimated that 7\% of Kenyan adults are infected with HIV. Measured prevalence levels among young women rise quickly with age (3\% are infected in the 15-19 age group and 9\% are in the 20-24 age group). Among men, prevalence reaches its peak (8.8\%) in the 40-44 age group (Central Bureau of Statistics, Kenya 2004).

\section{b. HIV/AIDS Awareness}

A number of institutions are currently implementing HIV/AIDS prevention programs in Kenya. These programs involve schools, health clinics, and the media. The Government of Kenya created the National AIDS Control Council (NACC) in 2000 to coordinate all HIV/AIDS activities in the country. Voluntary Counseling and Testing (VCT) services are available in each district. Radio programs on HIV/AIDS can be heard daily. Population Services International conducts social marketing of "Trust" condoms at the very low cost of 3 condoms for 12 US cents. Large wall-painted advertisements for Trust Condoms are present everywhere from large towns to rural villages. A number of 
NGOs are implementing HIV/AIDS prevention programs in schools, in churches and for specific target groups.

\section{c. Government Policy on HIV/AIDS education}

The great majority of Kenyan children attend at least some primary school, grades 1-8, but most do not attend secondary school. In 1999, the Kenyan government established a national curriculum on HIV/AIDS education to reach children in primary school. The national curriculum was developed with the assistance of UNICEF, and was the outcome of an extensive consultation process within Kenyan society that included many stakeholders, including religious groups. The Ministry has sent books covering the curriculum to all schools.

The primary school HIV/AIDS curriculum teaches basic medical facts about AIDS, HIV transmission, prevention, and care for people living with AIDS. It stresses abstinence as the most effective way to prevent pregnancies and infection with sexually transmitted diseases. Teachers are not trained to promote condoms. However, teachers have a fair amount of discretion in answering students' questions on condoms, and the

official Facilitator's Handbook recommends that teachers organize a debate among students on whether condom use should be taught to primary school students (page 66).

Individual schools and teachers effectively have a lot of discretion about whether to teach about HIV/AIDS. No specific times are set aside on the timetable for HIV/AIDS education. Schools tend to be focused on the exams students take at the end of primary school, and HIV/AIDS is not examined as a separate subject, although questions on HIV/AIDS are included in exams on other subjects. Most upper primary teachers have been trained to teach particular subject matter, such as math, and see this as their primary 
responsibility. Moreover, many do not feel competent to teach about HIV/AIDS. In many cases no teachers have been assigned specific responsibility for teaching the subject. Thus HIV/AIDS is often not covered very well in practice, despite the development of the national curriculum. In response, the Kenya Ministry of Education, Science and Technology (MOEST) has trained trainers to provide in-service courses for teachers on HIV/AIDS education.

\section{Program Description}

Four interventions took place in the same area: 1 ) training teachers in the HIV/AIDSeducation curriculum designed for primary schools by the Kenyan Government; 2) encouraging students to debate the role of condoms and to write essays about how they can protect themselves from HIV/AIDS; 3) informing teenagers about variation in HIV rates by age and gender (Dupas, 2005); and 4) reducing the cost of education by providing free uniforms, with the aim of keeping children in school longer.

\section{a. Teacher Training on HIV/AIDS curriculum}

The Kenyan government cannot implement the teacher training program on HIV/AIDS education everywhere simultaneously due to insufficient trainers and other resources. The training is thus being phased in over several years, as funds are made available. This creates a unique opportunity to rigorously evaluate the impact of the program using a randomized design. With the assistance of International Child Support (ICS), a nongovernmental organization working in Western Kenya, and funding from the Partnership

for Child Development (PCD), the MOEST trained teachers in three districts of Western 
Province between September 2002 and June 2003. All the schools that were selected to participate in the study agreed to participate. Each chose three upper primary teachers to participate in the 5-day training program. ${ }^{3}$ Attendance at the trainings was high (93\%).

The training sessions were conducted jointly by one facilitator from the AIDS Control Unit of the Ministry of Education (ACU-MOEST), two facilitators from the Kenya Institute of Education (KIE), and one trained staff member from ICS. The teacher training covered a wide range of topics, including basic facts on HIV/AIDS, condom demonstration, information on Voluntary Counseling and Testing, and AIDS education methodology. The participants reviewed material in the HIV/AIDS Facilitator's Handbook, learned both how to discuss HIV/AIDS issues as part of classes devoted to other topics and how to devote full-period lessons to HIV/AIDS activities, and prepared lesson plans under facilitators' supervision. At the end of the training, teachers were asked to prepare an "action plan" for HIV/AIDS education in their school, including how they would reach out to the other teachers in the school and integrate HIV/AIDS into the timetable.

In addition to delivering the classroom-based activities, trained teachers were advised to set up health clubs to encourage HIV avoidance through active learning activities such as role plays. Health clubs were monitored through school visits. A year after the training, $86 \%$ of the schools whose teachers had been trained had established health clubs. Trained teachers who had maintained an active health club were given a tshirt with a red ribbon and the message: "PAMOJA TUANGAMIZE UKIMWI" (Together, let's crush AIDS). Students who were members of the health club received red

\footnotetext{
${ }^{3}$ There are 14 teachers per school on average, so the training affected $21 \%$ of teachers in program schools
} 
ribbon pins to put on their school uniforms. Small grants of up to US\$50 were provided for health clubs that submitted a proposal to organize HIV/AIDS awareness activities for youth in and out of school. In the first year, $67 \%$ of the schools submitted a proposal that was approved.

Overall the teacher training and health club follow-up cost $\$ 550$ per school ${ }^{4}$. While the Kenyan government’s HIV/AIDS teacher training program does not necessarily represent an ideal program, it is financially, politically, and culturally feasible to scale, and thus seems worth evaluating.

\section{b. Debates on condoms, essay competition}

Half the schools that had received teacher training reinforcement were encouraged to organize a debate in 2005. The motion of the debate was: "School children should be taught how to use condoms”, a motion suggested in the official Facilitator's Handbook (p. 66, KIE 1999). All students in grades 7 and 8 were supposed to attend the debate. The debate was followed by an essay competition for students in grades 7 and 8 . The essay question was: "Discuss ways in which you can protect yourself from HIV infection now and at later ages in your life". The debates were not graded by teachers from the school, but by outside teachers hired by ICS during school break. In each school, a school bag was given as a prize for the best essays by a boy and by a girl in each of grades 7 and 8 .

\footnotetext{
on average. Schools were encouraged to send at least one female teacher to the training; headmasters were encouraged to attend themselves or to send their deputy.

${ }^{4}$ The costs included: full board accommodation of trainees and trainers for 5 nights; fare refund to and from the training venue for trainees and trainers); facilitation fee paid to trainers; cost of trainees' time; a set of 4 textbooks per trainee (Facilitator's handbook + 3 students textbooks); handouts and stationery; issuance of training certificates for trainees; anti-AIDS T-shirts for trainees; anti-AIDS badges for health club members at school; mini-grants for health clubs who submit a proposal.
} 
Both debates and essay writing are established practices in Kenyan schools, and teachers agreed to organize these activities in 95\% of sampled schools.

\section{c. Informing students about the profile of HIV prevalence by age and sex (Dupas, 2005)}

Cross-generational sex is associated with a higher risk of HIV infection for adolescent girls than sex with same-age partners, but many adolescent girls seem unaware of this. Information on the distribution of HIV infections by age and gender is typically not given to adolescents by their teachers because it is not covered by the HIV curriculum and was not included in the teacher training.

Dupas (2005) evaluates an intervention conducted in the fall of 2004, in which students in grade 8 were provided statistics on the prevalence of HIV, split by age and gender. The intervention also included the screening of a 10 minute video, "Sarah: The Trap”. This intervention was implemented both in schools where teachers had been trained and in schools where teachers had not been trained.

\section{d. Reducing the cost of education}

For HIV/AIDS education programs to be justified, they must not only be effective, but also more effective than alternative uses of the necessary resources. One natural alternative use for these resources is helping students stay in school longer. Since girls who become pregnant typically face strong social pressure to leave school (although legally they are entitled to attend), reducing the cost of education raises the opportunity cost of pregnancy and thus of unprotected sex. 
Since school fees were abolished in Kenya in 2003, school uniforms are the main direct financial barrier to access to education at the primary level. A uniform costs about $\$ 6$, a substantial expense for parents in a country where the GDP per capital is $\$ 360$ (World Bank, 2002).

Between February and July 2003, ICS distributed a free school uniform to each student who was enrolled in grade 6 in January 2003 (students enrolled in grade 6 are on average 14 years old). In total, about 10,000 uniforms were distributed. In order to avoid creating incentives for students to transfer between schools, ICS field officers visited all the schools to collect baseline enrollment data before announcing the program—only children enrolled at the time of the baseline were eligible for the uniform program. In the fall of 2004, ICS distributed a second uniform to the same students if they were still enrolled in the same school. It was announced at the onset of the program that students still enrolled in school would be eligible for a second uniform.

\section{e. Selection of Schools and Program Design}

The program took place in two rural districts of Western Kenya: Bungoma and ButereMumias. The study is based on a sample of 328 schools. Among them, 163 were randomly chosen for the teacher training. The randomization was done by the generation of a random number, after stratifying by the geographical division of the school, average performance of the school on the Kenya Certificate of Primary Education exam of 2001, and the gender ratio among upper primary students. 
In addition, 163 schools were randomly selected to receive uniforms, after stratifying by whether or not the school was receiving training reinforcement on HIV education and by geographical location, school achievement and gender ratio.

In 71 schools, teenagers were given information on HIV prevalence by sex and age. Among these 71 schools, 36 schools were randomly chosen among schools that did not receive the teacher training reinforcement and 35 schools were randomly chosen among schools where the teacher training reinforcement was provided (Dupas, 2005).

Among the 163 schools selected for teacher training, 82 were randomly selected for the condom debates and essay contest after stratifying by whether or not the school was receiving uniforms.

To summarize, the sample of 328 schools is divided into 6 groups as follows:

\section{SUMMARY OF PROGRAM DESIGN}

\begin{tabular}{|cccccc|}
\hline Group & $\begin{array}{l}\text { Number } \\
\text { of } \\
\text { Schools }\end{array}$ & $\begin{array}{l}\text { National } \\
\text { Program }\end{array}$ & $\begin{array}{l}\text { Teacher } \\
\text { training } \\
\text { Reinforcement } \\
\text { (Spring 2003) }\end{array}$ & $\begin{array}{l}\text { Condom } \\
\text { Debate and } \\
\text { Essay } \\
\text { (Spring 2005) }\end{array}$ & $\begin{array}{l}\text { Reducing the } \\
\text { Cost of } \\
\text { Education } \\
\text { (Spring 2003 } \\
\text { and Fall 2004) }\end{array}$ \\
\hline 1 & 88 & Yes & & & \\
2 & 41 & Yes & Yes & Yes & \\
3 & 42 & Yes & Yes & & Yes \\
4 & 83 & Yes & & & Yes \\
5 & 40 & Yes & Yes & Yes & Yes \\
6 & 40 & Yes & Yes & &
\end{tabular}

In each of these 6 groups, a fifth of the schools received information on the age-profile of HIV prevalence by gender in the second semester of 2004. 


\section{The Data and Estimation Strategy}

\section{a. The Data}

The baseline sample for the evaluation consists of the 74,000 students who were enrolled in grades 5 to 8 in any of the 328 sampled schools in January 2003. The study also involved about 3,000 upper primary teachers, of whom 445 participated in the HIV training program. In order to trace the impact of the different interventions, we collected data on several intermediate outcomes, but our main measure of whether behavior changed is the rate of childbearing among the girls enrolled in school at the baseline.

\section{- Teaching about HIV/AIDS}

To determine if the teacher training intervention increased teaching about HIV/AIDS, ICS field officers conducted interviews with teachers as well as focus group discussions with students and asked whether HIV/AIDS had been mentioned in any of their classes in the past weeks. Students were also asked what they knew about HIV/AIDS, whether the teachers had mentioned condoms, and if yes, what had been said.

\section{- School enrollment and attendance.}

In order to determine if reducing the cost of school reduced dropout rates, ICS field officers conducted 6 school visits, during which they conducted a roll call using the list of students enrolled at the baseline, and enquired about the whereabouts of the absent students: are they still enrolled in this school? Have they changed school? Have they dropped out?

\section{- Knowledge, attitudes, and self-reported behaviors}

A Knowledge, Attitude and Practice (KAP) survey was conducted among baseline students who were still in school in 2005. The survey was a written, anonymous 
questionnaire, administered in Kiswahili, filled out in class by students enrolled in grades 6, 7 and 8 in the spring of 2005. Questions were drawn from the national curriculum. The KAP survey did not ask questions about condoms but did include an open-ended question about how HIV/AIDS can be prevented, and we recorded the frequency with which condoms were mentioned.

\section{- Childbearing}

Because data on self-reported behavior may be contaminated by reporting bias, our main measure of whether the programs changed the probability that children engaged in risky behavior is the incidence of pregnancy and childbearing among girls in our sample. In addition to being an important outcome in its own right, in this primary-school-age population, childbearing is a proxy for risky sexual activity, as unprotected sex can lead to both pregnancy and HIV/AIDS.

Information on childbearing and marital status was obtained for all girls in the sample during six visits to each sampled primary school in the 36-month period following the intervention. At each visit, the list of all students in the baseline sample was read aloud to pupils enrolled in upper grades at the time of the visit, and for each of the baseline students the following questions were asked: Is "Mary" still in school? If yes, in what grade? In what school? Does she still live in the area? Is she married? Does she have any children? If so, how many? Is she pregnant?

Checks suggest this technique of collecting childbearing and marital outcomes generates accurate data. Among a sub-sample of 282 teenage girls that were tracked at their home and interviewed, $88 \%$ of those who were reported as having started childbearing by their former schoolmates had indeed started childbearing, and 92\% of 
those who were reported as not having started childbearing had indeed not started. The accuracy rates were similar across groups.

Of course childbearing is an imperfect proxy for risky sexual behavior. While information on childbearing by girls is likely to be relatively good, information on whether boys have had children is likely not as good. Abortion and anal sex could both reduce the correlation between the incidence of childbearing and the risk of HIV infection. Neither is easy to collect data on, especially as abortion is illegal in Kenya.

The teacher training program could potentially change some students' behavior in ways that increase the probability of childbearing without increasing the probability of HIV/AIDS infection. For example if, following the training, girls are convinced of the importance of marriage and being faithful, they might be more likely to marry, and to have a child. If their partner is faithful as well, they may be less likely to get HIV/AIDS. For this reason, we also collect data on whether those exposed to the program are more likely to be married. We are also in the process of conducting home visits to obtain more information on the father of the child.

Whatever its limitations, data on childbearing is likely to be more reliable than self-reported sexual behavior data. Ultimately, however, the best measure of the effect of the program would be biomarkers - tests for HIV infection or other STDs. Collecting biomarker data was difficult to do while students were still minors. We hope to be able to conduct such a study in the future. 


\section{b. Estimation Strategy}

Since all the programs were randomly assigned, schools should be similar in expectation across groups, along both observable and unobservable dimensions. Baseline statistics, presented in Table 1, confirm that there was no significant difference in observable school characteristics across groups at the start of the program. Thus the effectiveness of each program component can be evaluated by simple comparison of the outcomes in the various treatment groups.

In practice, this is implemented in a simple regression framework. For each individual-level outcome, the estimation equation is:

$$
O_{i s}=Z_{\text {is }}^{\prime} \beta+T_{s}^{\prime} \gamma+\mu_{s}+\varepsilon_{\text {is }}
$$

where $O_{i s}$ is the outcome for student $i$ enrolled in school $s$ at baseline. $Z_{i s}$ is a vector of indicator variables for each grade, and $T_{s}$ is a vector of indicator variables for each treatment. Error terms are assumed to be independent across schools, but are allowed to be correlated across observations in the same school. We have run regressions with and without individual (age) and school control variables. Not surprisingly given the randomized nature of the program, the results are essentially identical, so in these tables we report only the results without these control variables. We have also run specifications where the programs were allowed to have interactions with each other. For

example, the effect of the uniform program was allowed to be different in teacher training schools and in other schools. It turns out that none of the coefficients of these interactions were significant, and that it is impossible to reject the hypothesis that the effects of these programs are purely additive. For brevity, we also omit these results. 


\section{Results}

\subsection{Delivery of HIV/AIDS education}

To measure the extent to which HIV/AIDS education was delivered in schools, focus group discussions were held with students enrolled in grades 6 and 7 in early 2004, that is 12 to 18 months after the teacher training took place. The focus group discussions were conducted separately with 5 boys and 5 girls randomly chosen among students present in class during an unannounced visit. They were asked when HIV/AIDS issues were last mentioned in class, in what context the teachers mentioned HIV/AIDS, and what they said. Students were also asked about their other sources of information on AIDS.

Table 2 shows the data averaged by whether schools participated in the teacher training program or not. In regular schools, $73 \%$ of the focus groups declared that some teachers teach about HIV/AIDS. In teacher training schools, this increased by 14 percentage points, or $20 \%$. This difference is significant at the $99 \%$ confidence level. Teachers in teacher training schools used a wider array of methodologies to integrate HIV/AIDS education into the school. They are 8 percentage points (16\%) more likely to mention HIV/AIDS in passing while teaching a core subject, and 17 percentage points (50\%) more likely to devote "game time" (that is, time outside of a regularly scheduled class, that would ordinarily be for recess or PE) to HIV/AIDS issues. Considerably more time was devoted to HIV/AIDS in treatment schools: teachers were 50\% more likely to have mentioned HIV/AIDS in the last week.

In addition, the great majority of schools whose teachers were trained created a health club as a means to convey HIV prevention messages to the students and the school 
community at large: $68 \%$ of students in teacher-training schools report that there is an active health club in their schools, compared to $5 \%$ in regular schools.

\subsection{Knowledge, attitudes, and behavior of Students After Two years}

A self-administered, anonymous Knowledge, Attitudes and Practice (KAP) survey was conducted among students enrolled in grades 6, 7, and 8 in 2005. The survey was conducted more than two years after the teacher training and after two rounds of uniform distribution, but only a few months after the debates on condoms and essay competitions.

Table 3 shows the results of OLS regressions for knowledge outcomes. Besides increasing by 5.7 percentage points (15\%) the likelihood that boys mention abstinence as a means to prevent HIV infection (column 6), the teacher training program had no impact on practical knowledge. Participation in a debate on condoms increased knowledge about condoms among both girls and boys. Compared to other girls, girls in condoms debate schools are 7.9 percentage points (25\%) more likely to mention condom use as a way to protect oneself from HIV infection (column 7); 6.7 percentage points (14\%) more likely to think that condoms can prevent pregnancy (column 9); and 7.0 percentage points (13\%) more likely to think that condoms can prevent HIV transmission (column 11). Compared to other boys, boys in condom debate schools are 6.1 percentage points (13\%) more likely to mention condom use as a way to protect oneself from HIV infection (column 8) and 6.1 percentage points (9\%) more likely to think that condoms can prevent pregnancy (column 10).

Table 4 shows the results of OLS regressions for a series of attitudinal outcomes. The teacher training program made girls more tolerant of people who are HIV positive: 
girls in teacher training schools are more likely to say they would care for a relative who has AIDS or to buy food from a shopkeeper who has HIV (Table 4, columns 1 and 3).

One of the questions asked to the students was the following: "If one cannot abstain, is it OK to use a condom before marriage?” The teacher training did not affect how students answered the question (columns 5 and 6). However, condom debates increased the likelihood that girls answer positively by 3.1 percentage points, corresponding to a $7 \%$ increase.

The teacher training had no effect on common measures of the skills needed to resist peer pressure. On the other hand, girls for whom the cost of education was reduced are more likely to be confident that they can say "no" to a partner who wants to have sex (Table 4, column 11). Boys for whom the cost of education was reduced are more likely to be confident that they will never get HIV (Table 4, column 14).

Table 5 shows the results of OLS regressions for a series of self-reported behaviors. The teacher training program had no effect on self-reported sexual activity. It increased the number of boys reporting having ever used a condom by 2.7 percentage points or $8 \%$ (column 6), but did not increase significantly the likelihood that they report having used a condom at their last sexual encounter (column 8). The reduction in the cost of education reduced the likelihood that girls report having ever had sex by 2.3 percentage points (13\%) (column 1). Condom debates and essays increased the likelihood that boys report having used a condom at last encounter by 5.6 percentage points corresponding to a $20 \%$ increase (column 8 ). 


\subsection{Dropout and Childbearing Rates}

Table 6 presents the results of OLS estimates of the effects of each program component on the dropout and childbearing rates among baseline students (that is, students enrolled in upper primary school at the onset of the program). The condom debates and essay competitions took place too recently for us to be able to detect a reduction in childbearing from this intervention (the most recent childbearing data were collected 8 months after the debates were organized). However, we can look at the impact of the teacher training and the reduction in the cost of education over a 36-month period. While the teacher training had no impact on retention rates, the reduction in the cost of education helped students stay in school longer. Girls in schools were free uniforms were provided are 2.5 percentage points less likely to have dropped out (column 1). This corresponds to a $15 \%$ decrease. For boys, the decrease is also around 15\% (column 2). Reducing the cost of education thus helped students stay in school longer, and, consequently, decreased the likelihood that they get married and have children. Girls in schools where free uniforms were provided are 1.5 percentage points less likely to have started childbearing (column 3). This corresponds to almost a 10\% decrease in teen childbearing. They are also 1.4 percentage points (or 12\%) less likely to be married. Among boys, those in schools with reduction in the cost of education are 0.8 percentage points, or $40 \%$, less likely to be married (column 5). Overall, these results suggest that reducing the cost of education generates effective incentives for teenagers to avoid teen pregnancy or marriage. In rural Western Kenya, social pressures are likely to make these incompatible with school attendance for most pupils. 
In comparison, the teacher training had no effect on the incidence of teen childbearing. However, conditional on having started childbearing, girls in teacher training schools are 4.3 percentage points (6\%) more likely to be married to the father of their child.

Given the lack of effect on pregnancy and the fact that the marriage rate has increased, the likely impact of the teacher training on HIV transmission rates is unclear. On one hand, early marriage could be associated with a decrease in the rate of partner change among teenagers, and thus reduced spread of HIV. On the other hand, teenage girls might get infected with HIV within their marriage if they marry older partners, whose infection rate is higher than that of teenage boys. In order to better understand the impact of the teacher training, we are currently conducting home visits to collect information on the characteristics of the partners of girls who have begun childbearing.

Dupas (2005) finds that informing girls about variation in HIV rates by age and sex leads girls to reduce the particularly risky unprotected cross-generational partnerships. A year after the intervention, girls who had received information on the profile of HIV infections by age and gender were $65 \%$ less likely to have gotten pregnant by adult partners. While self-reported sexual activity with same-age partners increased, childbearing by teenage couples did not increase. Overall, childbearing rates fell by $32 \%$ among girls who were exposed to the information on relative risks.

These results, along with the preliminary findings that the debates on condoms and an essay competition on ways of protecting oneself from HIV/AIDS increased students' self-reported use of condoms, suggest that teenagers are responsive to information on relative risks. 


\section{Cost per Teen Pregnancy Averted}

Table 7 shows the results of extremely preliminary cost-effectiveness calculations based on the point estimates of the effects found in Table 6. The assumptions we make are the following.

Teacher Training - We assume that the impact of the teacher training decreases steadily over time, and completely disappears after either 4 (Case 1) or 8 years (Case 2). The cost of the teacher training includes the cost of the time spent by teachers in training, but not their time teaching the HIV/AIDS curriculum.

Reducing the cost of education - Since we focus on the cost per pregnancy averted, we do not include the cost of reducing the cost of education for boys. We consider that reducing the cost of education benefits only the direct recipients of the program, that is, we ignore possible spillovers onto their siblings. We also ignore the potential increase in future earnings for students who staid in school longer thanks to the program. We use two ways of computing the cost of implementing the program for girls. First, we compute the cost to the public budget of providing uniforms to girls (Case A). Second, since reducing the cost of education by paying for uniforms is a transfer, we treat the cost of the program as its deadweight loss, assumed to be $40 \%$ of the revenues needed to implement the program (Case B). We assume a discount rate of 5\% per year.

We find that reducing the cost of education costs at least $\$ 300$ per pregnancy averted, and the teacher training costs at least $\$ 525$ per pregnancy averted. In comparison, informing girls of the age-profile of HIV prevalence among men costs $\$ 91$ per pregnancy averted. 


\section{Conclusion}

Training teachers in Kenya for the HIV/AIDS curriculum did not lead to any reduction in teen pregnancy but increased the likelihood that teen pregnancies occur within marriage. Debates over condoms and opportunities to write essays on ways of protecting oneself against HIV/AIDS led to increased self-reported use of condoms without an increase in self-reported sexual activity. Reductions in the cost of schooling led to reductions in the dropout rates and reductions in teen pregnancies.

A definitive assessment of the impact of these programs will require biomarker tests. These could help determine whether the increase in self-reported use of condoms associated with the debates over condoms corresponds to actual reduction in HIV/AIDS.

Similarly, the increased marriage rates among girls exposed to teacher training could be indicative of either lower risk due to formation of more stable partnerships, or higher risk due to partnerships with older men. Older men are more ready to marry, but have higher HIV rates, than primary school boys. 


\section{References}

Aplasca, M. R., et al. (1995), "Results of a Model AIDS Prevention Program for High School Students in the Philippines.” Aids London Current Science, 1995

Aral, S. O. and T. A. Peterman (1996). "Measuring Outcomes of Behavioural Interventions for STD/HIV Prevention.” International Journal of STD \& AIDS 1996; 7 (Suppl. 2): 30-38

Bundy, D. (2002). Education and HIV/AIDS : A Window of Hope. World Bank, Washington DC.

Central Bureau of Statistics (CBS) [Kenya], Ministry of Health (MOH) [Kenya], and ORC Macro. (2004). Kenya Demographic and Health Survey 2003. Caverton, Maryland: CBS, MOH, and ORC Macro.

DFID (2004). "MEMA kwa Vijana: randomised controlled trial of an adolescent sexual health programme in rural Mwanza, Tanzania”, DFID Knowledge Programme on HIV/AIDS and STIs, London School of Hygiene and Tropical Medicine (LSHTM).

Dupas, P. (2005). "Relative Risks and the Market for Sex: Teenagers, Sugar Daddies and HIV in Kenya”, mimeo, PSE.

Gallant, M. and Maticka-Tyndale, E. (2004). "School-based HIV Prevention Programmes for African Youth" Social Science \& Medicine 58 1337-1351

Fawole, IO, et al. (1999) , “A School-Based AIDS Education Programme for Secondary School Students in Nigeria: a Review of Effectiveness”. Health Educ Res 1999 Oct;14(5):675-83

Hayes, R. J. et al. (2005). "The MEMA kwa Vijana Project: Design of a community randomised trial of an innovative adolescent sexual health intervention in rural Tanzania”, Contemporary Clinical Trials, Volume 26, Issue 4, Pages 430-442.

Jha P, et al. (2001). "Reducing HIV Transmission in Developing Countries." Science. 2001 Apr 13; 292 (5515): 224-5

Kelly, Michael (2000a). "Standing Education on its Head: Aspects of Schooling in a World with HIV/AIDS“, Current Issues in Comparative Education Volume 3, Number 1 http://www.tc.columbia.edu/cice/vol03nr1/mkart1.htm

Kelly, Michael (2000b) “The Encounter Between HIV and Education”, UNESCO. 
Kelly, Michael (2000c) "The Leadership Challenge and the Way Forward: HIV/AIDS and Education in Eastern and Southern Africa", African Development Forum, UNECA; http://www.uneca.org/adf2000/educ1.htm

KIE (1999). AIDS Education Facilitator's Handbook. Kenya Institute of Education, Nairobi.

Kim, N. et al. (1997). "Effectiveness of 40 Adolescent AIDS-Risk Reduction Interventions: a Quantitative Review.” Journal of Adolescent Health 20: 204-15.

Kinsman J, et al. (1999), "Implementation of a Comprehensive AIDS Education Programme for Schools in Masaka District, Uganda”, AIDS Care, Oct;11(5):591-601

Kirby, Douglas (1985). "The Effects of Selected Sexuality Education Programs: Toward a More Realistic View”, Journal of Sex Education and Therapy, p.28-37.

Kirby, Douglas (1995). "Sex and HIV/AIDS Education in Schools", British Journal of Medicine

Kirby, Douglas (1992). "School-Based Programs to Reduce Risk-Taking Behavior”, Journal of School Health, p.280-287, Vol. 62, No. 7

Kirby, Douglas, Richard Barth, Nancy Leland and Joyce Fetro, (1991) "Reducing the Risk: Impact of a New Curriculum on Sexual Risk-Taking”, Family Planning Perspectives, Vol. 23, Number 6.

Kirby, D. and Coyle, K. (1997). "School-Based Programs to Reduce Sexual Risk-Taking Behavior." Children and Youth Services Review 19(5): 415-36.

Kirby, Douglas et al. (1994) "School-Based Programs to Reduce Risk-Taking Behavior: A Review of Effectiveness”, Public Health Reports Vol. 109, No. 3

Klepp, Knut-Inge, Sidney Ndeki et al. (1997) "AIDS Education in Tanzania: Promoting risk Reduction Among Primary School Children”, American Journal of Public Health, Vol. 87(12), pp 1931-1936.

Mellanby, Alex, Fran Phelps et al. (1995) "School Sex Education: an Experimental Programme With Educational and Medical Benefits", British Journal of Medicine, 414-417.

Mensch, Barbara, Wesley Clark et al. (1999). "Premarital Sex and School Dropout in Kenya: Can Schools Make a Difference?”, Population Council WP No 124.

Shuey DA, et al. (1999). "Increased Sexual Abstinence Among In-School Adolescents as a Result of a School Health Education in Soroti district, Uganda” Health Education Research June; 14(3) 411-9. 
Stanton, B.F., et al. (1998) "Increased Protected Sex and Abstinence among Namibian Youth following a HIV Risk-Reduction Intervention: A Randomized, Longitudinal Study” AIDS, 12:2473-2480.

UNAIDS, 2002 Report on the Global HIV/AIDS Epidemic 


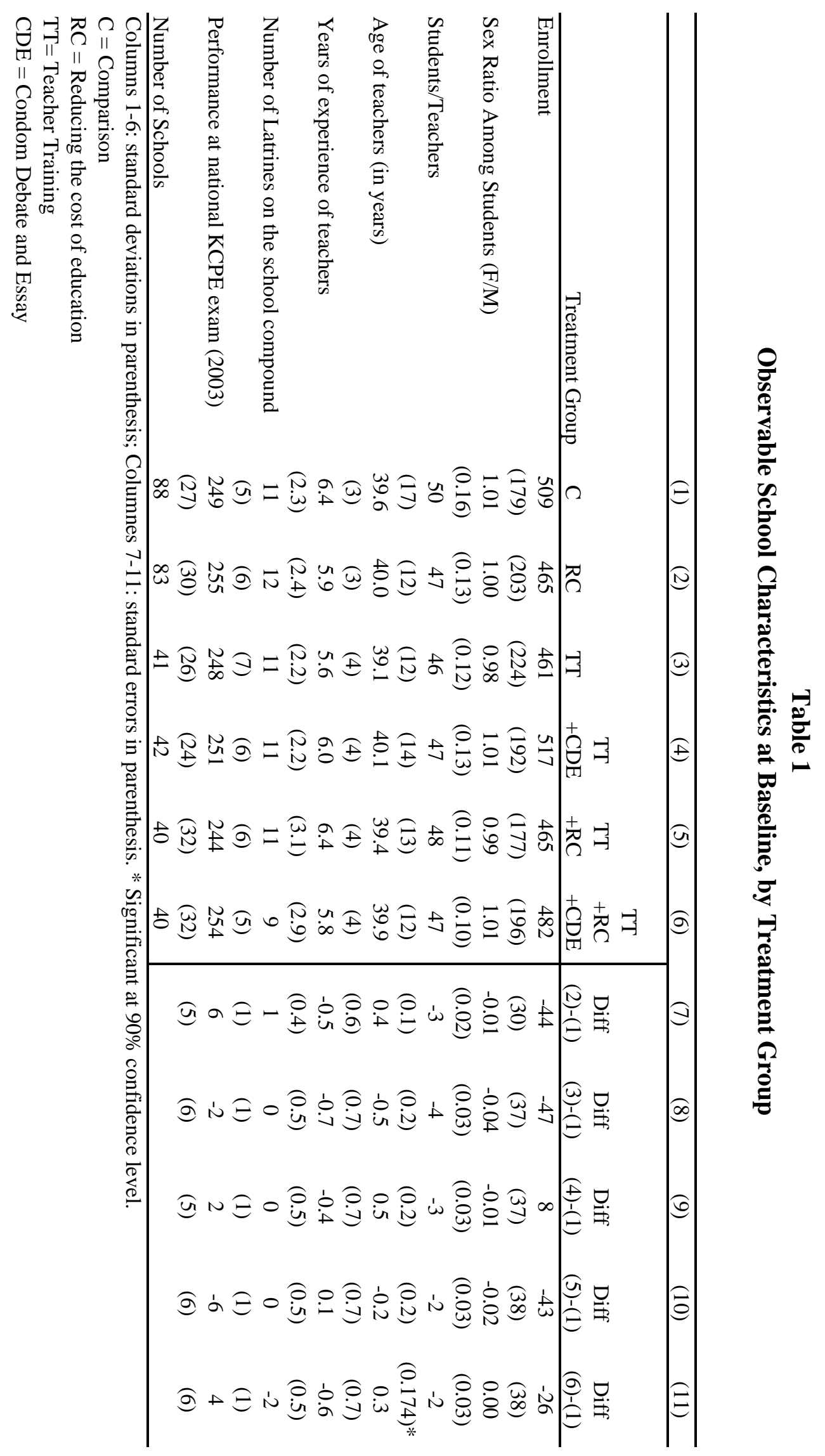




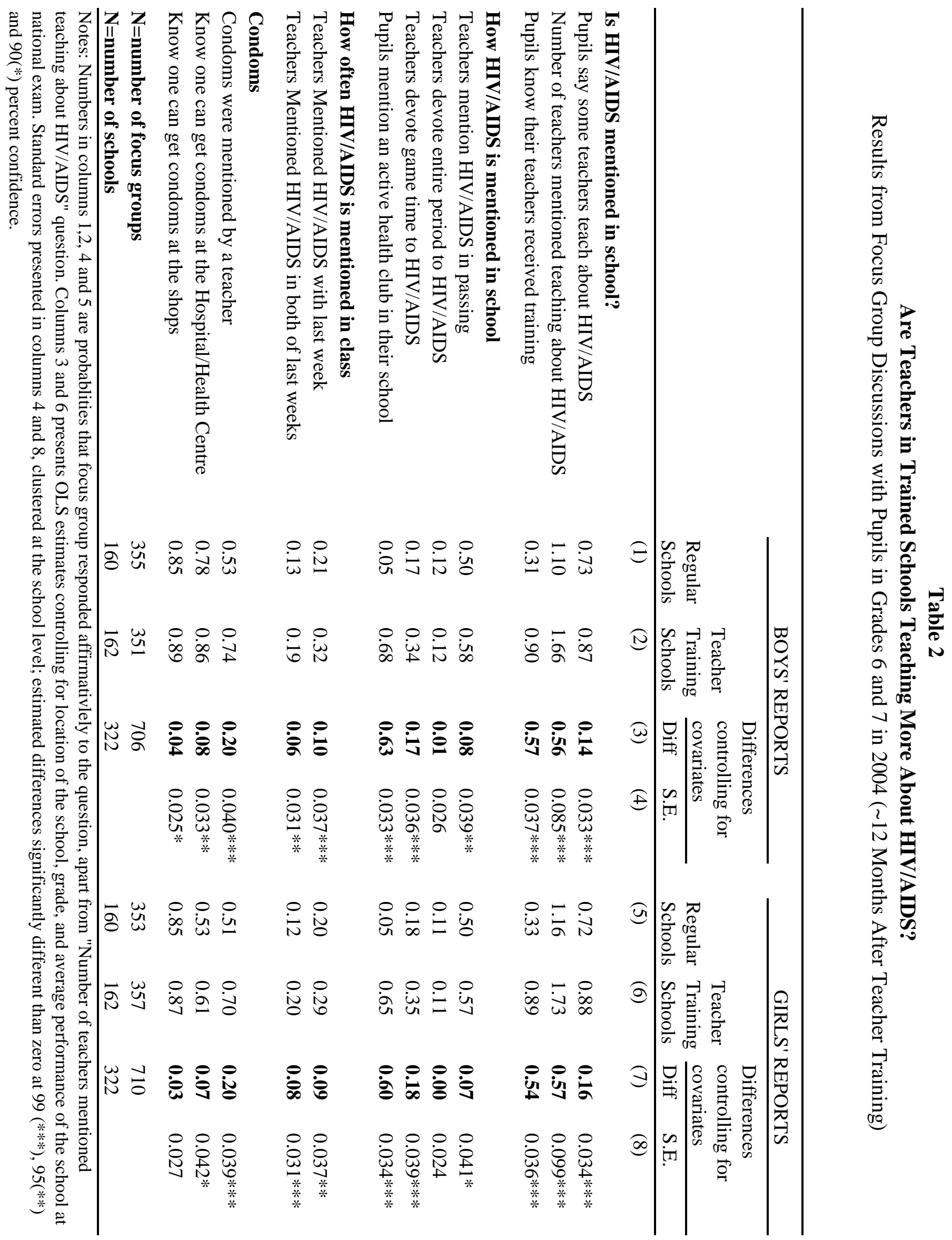



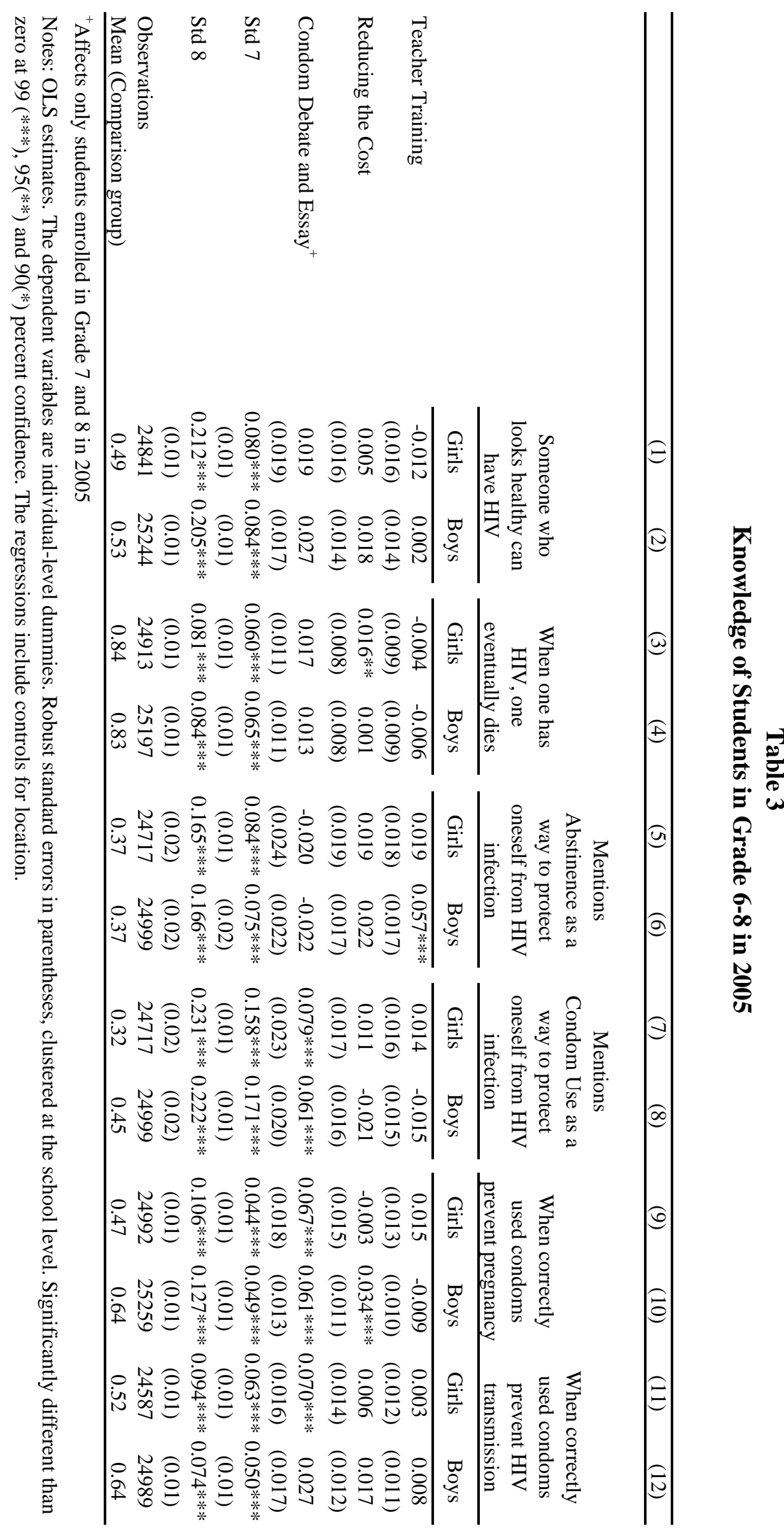


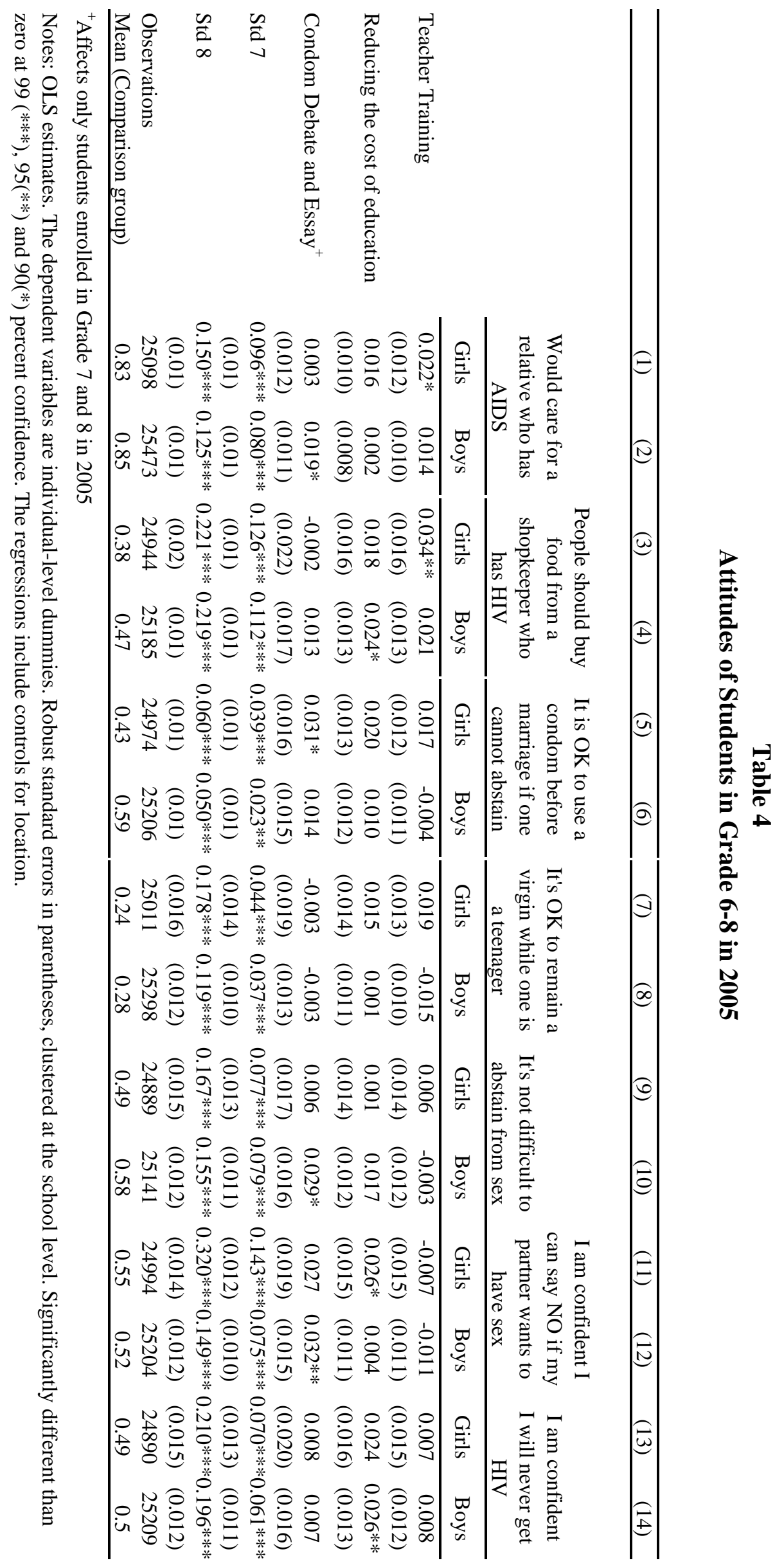




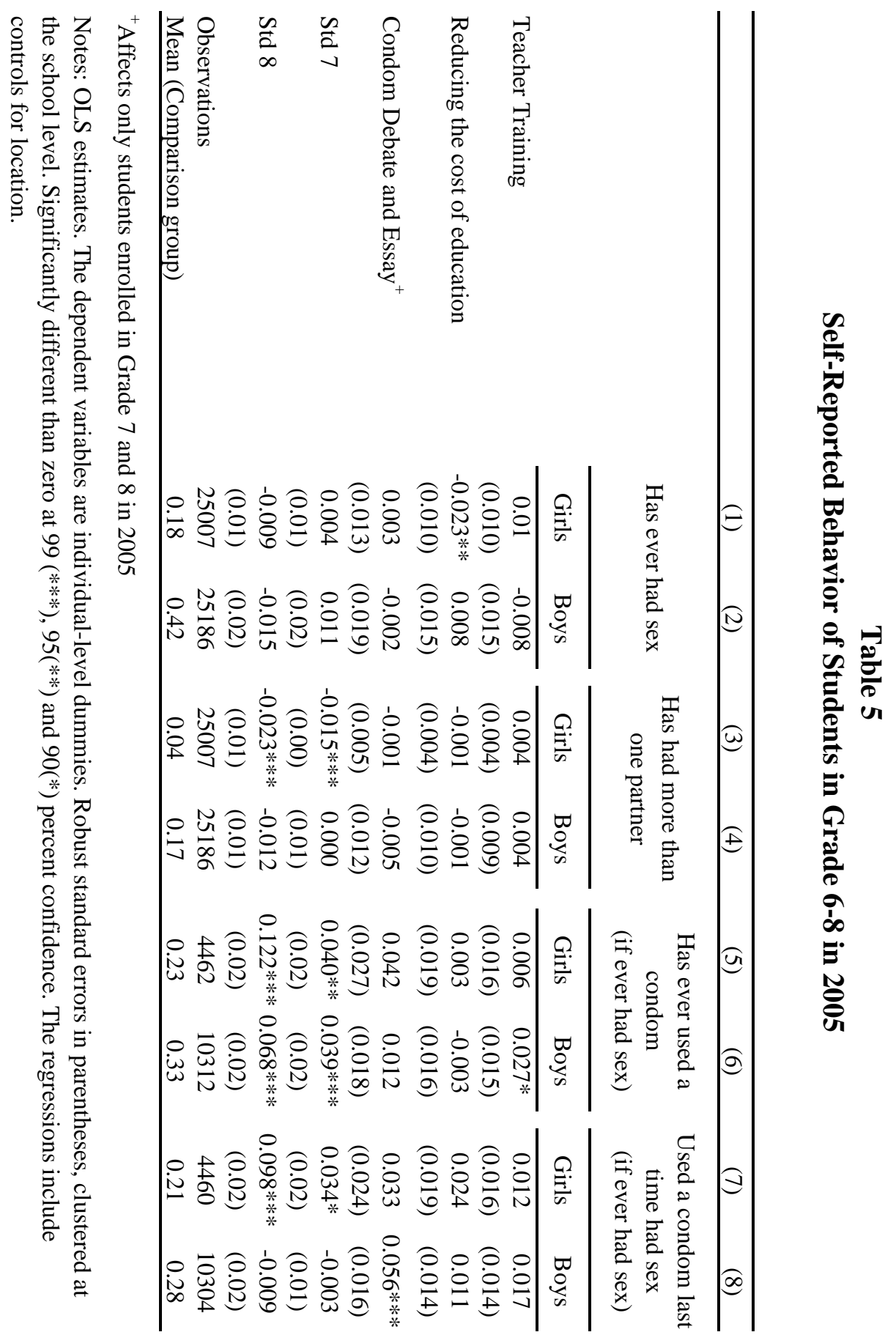




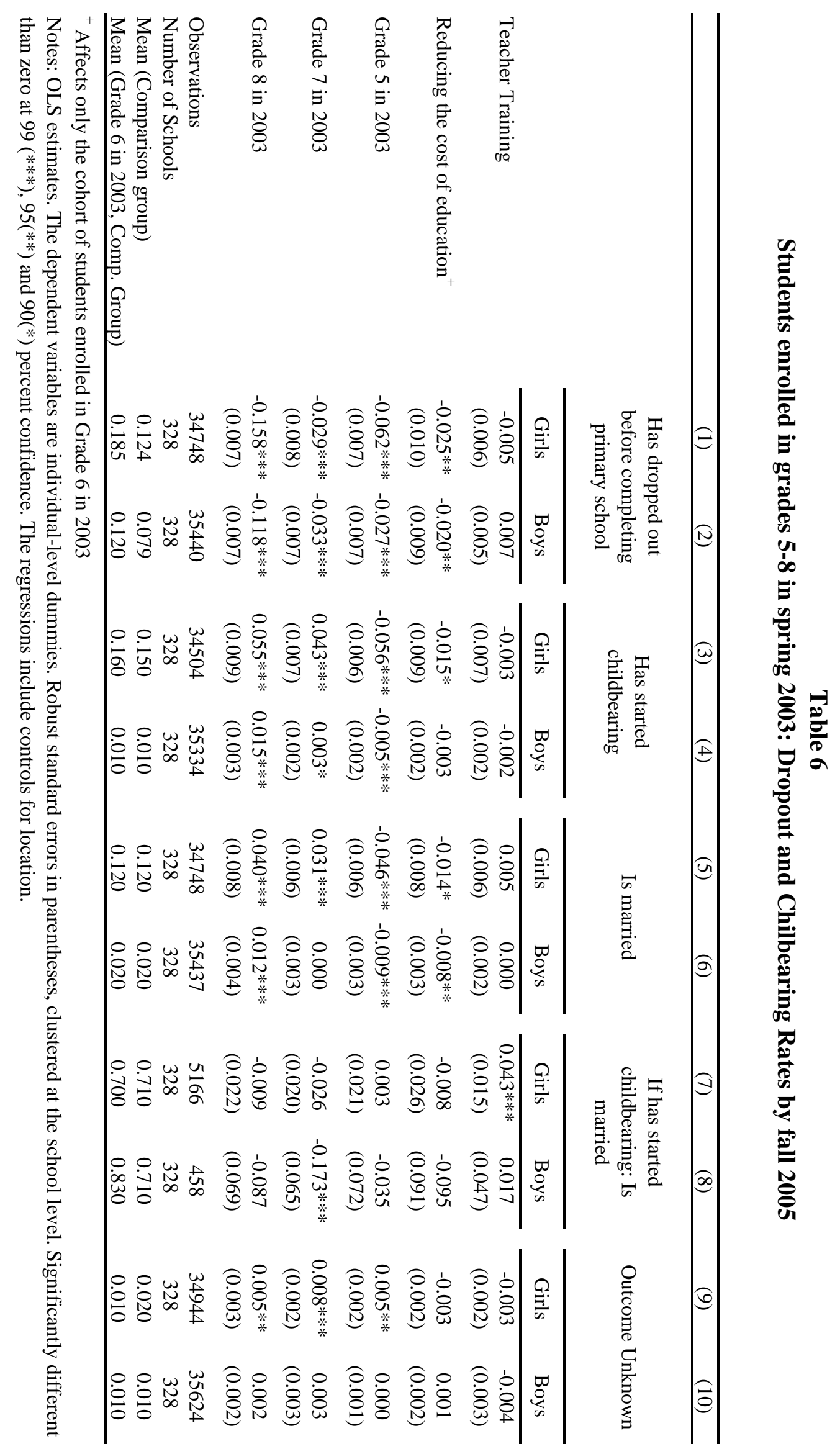




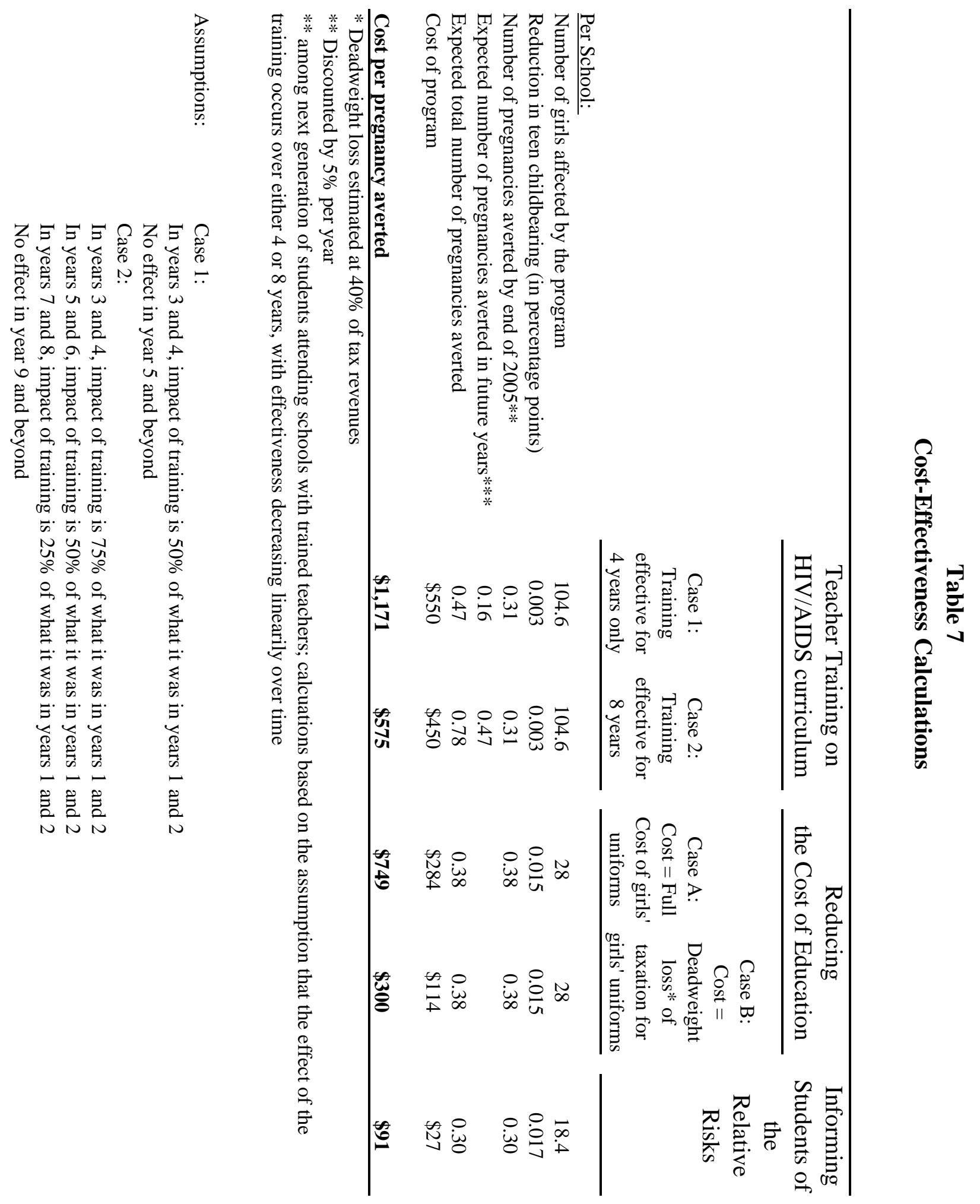

